\title{
MASC, a qualitative multi-attribute decision model for ex ante assessment of the sustainability of cropping systems
}

\author{
Walid SADOK ${ }^{1}$, Frédérique ANGEVIN ${ }^{2}$, Jacques-Eric BERGEZ ${ }^{3}$, Christian BocKSTALLER ${ }^{4}$, Bruno COLOMB $^{3}$, \\ Laurence GUICHARD ${ }^{5}$, Raymond REAU ${ }^{5}$, Antoine MESSÉAN ${ }^{2}$, Thierry DORÉ ${ }^{6 *}$ \\ ${ }^{1}$ INRA, UMR 211 INRA/AgroParisTech, BP 01, 78850 Thiverval-Grignon, France; Present address: Agronomy-Physiology Laboratory, \\ University of Florida, PO Box 110965, Gainesville, FL 32611-0965, USA \\ 2 INRA, UAR 1240 Eco-Innov, BP 01, 78850 Thiverval-Grignon, France \\ ${ }^{3}$ INRA, UMR1248 AGIR INRA/ENSAT, BP 52627 Auzeville, 31326 Castanet Tolosan, France \\ ${ }^{4}$ INRA, UMR 1121 Nancy-Université - INRA Nancy-Colmar, BP 20507, 68021 Colmar, France \\ ${ }^{5}$ INRA, UMR 211 INRA/AgroParisTech, BP 01, 78850 Thiverval-Grignon, France \\ ${ }^{6}$ AgroParisTech, UMR 211 INRA/AgroParisTech, BP 01, 78850 Thiverval-Grignon, France
}

(Accepted 16 January 2009)

\begin{abstract}
Realistic assessments of sustainability are often viewed as typical decision-making problems requiring multi-criteria decision-aid (MCDA) methods taking into account the conflicting objectives underlying the economic, social and environmental dimensions of sustainability, and the different sources of knowledge representing them. Some MCDA-based studies have resulted in the development of sustainable agricultural systems, but the new challenges facing agriculture and the increasing unpredictability of their driving forces highlight the need for faster ex ante ('Before-the-event') assessment frameworks. These frameworks should also (i) provide a more realistic assessment of sustainability, by integrating a wider range of informal knowledge, via the use of qualitative information; (ii) address alternative scales, such as cropping system level, improving granularity for the handling of sustainability issues and (iii) target a larger panel of decision-makers and contexts. We describe here the MASC model, which is at the center of a framework addressing these objectives. The MASC model has at its core a decision tree that breaks the sustainability assessment decisional problem down into simpler units as a function of sustainability dimensional structure (economic, social and environmental), generating a vector of 32 holistic 'mixed' (quantitative and qualitative) elementary criteria rating cropping systems. The assessment process involves the calculation of these criteria, their homogenization into qualitative information for input into the model and their aggregation throughout the decision tree based on 'If-Then' decision rules, entered by the user. We present the model and describe its first implementation for the evaluation of four cropping systems generated from expert knowledge, and discuss its relevance to the objectives cited above. The MASC model has several advantages over existing methods, due to its ability to handle qualitative information, its transparency, flexibility and feasibility.
\end{abstract}

cropping system / sustainability assessment / ex ante / MCDA / decision rules / qualitative multi-attribute decision models / DEXi

\section{INTRODUCTION}

The agricultural sector is currently at the confluence of an increasing number of new challenges such as market globalization, food crisis, bio-fuels, environmental concerns, and changes in legislation at the global and local scales that are threatening the future of agricultural systems in many areas of the world. Almost two decades ago the foreseeable uncertainties and threats conditioning the future of agricultural systems resulted in the development of the agricultural sustainability concept, which has been defined in many ways (Hansen,

* Corresponding author: thierry.dore@agroparistech.fr
1996; Christen, 1998), all highlighting its holistic and multidimensional nature and encompassing economic, social and environmental objectives.

Ever since the emergence of this concept, it has been claimed that the assessment of multidimensional sustainability is required for the implementation of new forms of sustainable agriculture (Neher, 1992; Schaller, 1993; Vereijken, 1997; den Biggelaar and Suvedi, 2000; Pacini et al., 2003; Gafsi et al., 2006). The first operational studies concluded that, for such assessments to be realistic, a 'methodological leap' was needed (i) to integrate knowledge of different types relating to economic, social and environmental objectives and (ii) to handle the conflicting aspects of these objectives (Munda et al., 
1994; Dent et al., 1995). One alternative involved considering sustainability assessment as a typical decision-making problem that could be handled by multi-criteria decision-aid (MCDA) methods (Munda et al., 1994; Munda, 2005). As a result, over the last ten years, a number of MCDA-based frameworks have been developed to facilitate the implementation of sustainable forms of agriculture (Rossing et al., 1997; Zander and Kächele, 1999; Loyce et al., 2002; Dogliotti et al., 2004, 2005).

However, the current pace at which new challenges are appearing and shaping agricultural sustainability and the increasing unpredictability of the driving forces behind them make it necessary to find alternative ways to address the questions of the representation and assessment of sustainability. First, these fluctuations make it increasingly necessary to develop fast ex ante (i.e., 'Before-the-event') sustainability evaluation frameworks that can represent and assess a large body of options in silico and rapidly identify innovative, alternative systems without the need for in-field assessments of all the possible options (European Commission, 2005; Van Ittersum et al., 2007; Meynard, 2008).

Second, there is a need to improve the 'granularity' of the spatio-temporal scales generally used in sustainability assessment studies, making it possible to target specific sustainability issues more efficiently. The smallest spatiotemporal unit addressed in sustainability assessment studies is generally the farming system (e.g., Häni et al., 2003; Dogliotti et al., 2005; Meyer-Aurich, 2005; Meul et al., 2008), whereas much of the impact of the environment and the impact of certain socioeconomic factors on farms are deeply rooted within smaller units, such as that of the cropping system - the level at which they are determined. These units, defined by Sebillotte (1990) as ' $a$ set of management procedures applied to a given, uniformly treated area, which may be a field, part of a field or a group of fields' are rarely considered in assessments of sustainability (Rosnoblet et al., 2006). Furthermore, in the few cases in which this scale has been specifically addressed (e.g., Mazzetto and Bonera, 2003), the number of sustainability criteria considered is strongly limited with respect to the holistic nature of the concept of sustainability. A more detailed assessment of cropping systems may make it possible to target and improve each of the systems making up the farming system, in a specific manner.

Third, many of the available MCDA-based frameworks are restrictive in terms of the type of information required and the types of decision-maker targeted. These restrictions on the type of information result from diverse contexts that cannot be addressed quantitatively being overlooked, thus limiting the range of innovative options assessed (Sadok et al., 2008). The restrictions on the type of decision-maker arise from the underlying decisional problem being addressed in a manner appropriate for only a small subset of decision-makers in many of these studies. Quantitative preference models, with formalisms that are 'opaque' or inaccessible to non-expert decision-makers, are often used. Dent et al. (1995) suggested that an assessment method is likely to be successful only if it uses the language of the decision-maker and represents all aspects of his knowledge, including empirical, non-formal aspects.

In a comparative review of the main MCDA families focusing on relevance for sustainability assessment, Sadok et al. (2008) suggested that 'mixed' or 'non classical' MCDA methods were particularly relevant for handling the above constraints, while being able to address more efficiently the multidimensional constraints of sustainability assessment (i.e., incomparability, non compensation and incommensurability of dimensions). This is particularly true for decision rule-based methods, which allow the use of qualitative input information and qualitative reasoning in the decision modeling process. Programs using these methods - often in the form of decision support systems (DSS) - are increasingly designed for use by more diverse decision-makers, with the provision of transparent communication interfaces (Matthies et al., 2007). Some of these approaches have been used successfully to assess specific problems in agricultural systems, such as the impact of these systems on soil quality (Bohanec et al., 2007) or the ecological/economic impact of genetically modified crops (Bohanec et al., 2008). However, to our knowledge, the use of such approaches to assess explicitly and simultaneously the social, economic and environmental dimensions of the sustainability of a given agricultural system - in this case cropping systems - has never been reported.

We describe here the MASC (for multi-attribute assessment of the sustainability of cropping systems) decision model, which was developed within a decision support system (DEXi), as a key element of a framework combining the ex ante generation and assessment of cropping systems. We present and discuss the decision model and its first implementation for the assessment of four cropping systems generated from expert knowledge.

\section{METHODS}

\subsection{The assessment framework}

The overall assessment framework consisted of a three-step approach (Fig. 1):

1. The generation of cropping systems, as inputs for the decision model. This step can be achieved with special computing tools (Dogliotti et al., 2003; Loyce et al., 2002; Bergez et al., 2008), based on expert knowledge (Lançon et al. 2008), or both.

2. Representation of each of the generated cropping systems as a vector of sustainability criteria expressed in qualitative terms and the processing of this vector by MASC to obtain a synthetic qualitative assessment of the overall (economic, social and environmental) sustainability of the cropping system.

3. Analysis and interpretation of the assessment results for the selection of alternative systems to be tested in field trials. If the decision-makers are not satisfied with the results, the framework offers the possibility of either 'adjusting' certain decision rules or, if necessary, testing a new set of improved cropping systems (Fig. 1). 


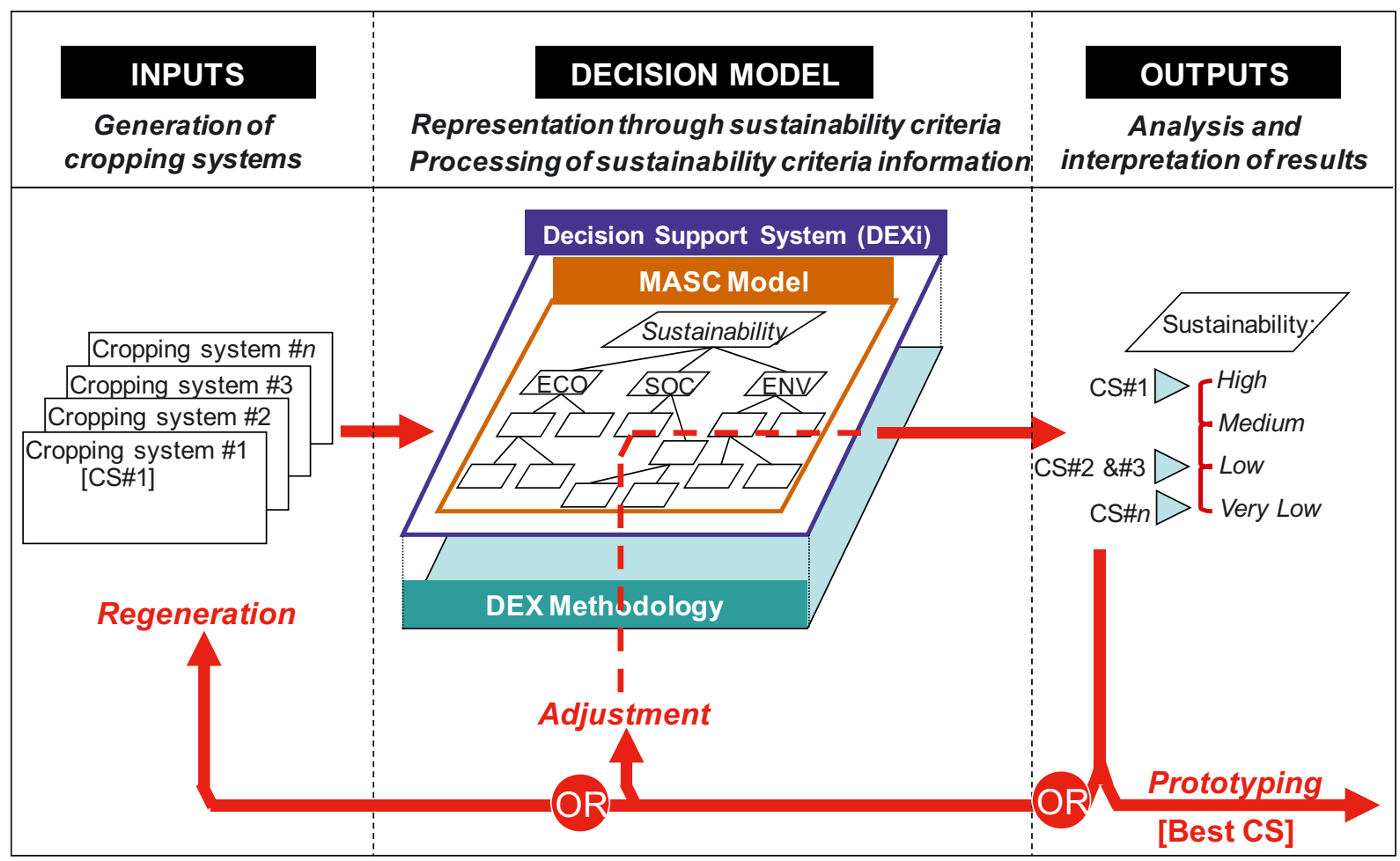

Figure 1. Structure of the framework generating and assessing ex ante the sustainability of cropping systems. After generation (in silico through models, from expert knowledge or both), the cropping systems (inputs) are represented as a vector of values for sustainability criteria, which are processed by the MASC decision model, implemented within a decision support system (DEXi). Depending on the evaluation results (outputs), a cropping system may be (i) selected for prototyping in the field (ii) re-submitted to the decision model with 'adjusted' choices in the evaluation process or (iii) discarded/improved, possibly requiring a new generation process.

\subsection{Methodological basis of MASC}

MASC is based on DEX methodology, and is implemented within a decision support system (DSS) called DEXi (Bohanec, 2003). It combines a hierarchical multi-attribute decision model and an expert system shell. Hierarchical multiattribute decision models are used in many classical MCDA approaches, such as the AHP (Analytic Hierarchy Process) or other MAUT/MAVT (Multi-Attribute Utility/Value Theory) methods (Saaty, 1980; Clemen, 1996; Figueira et al., 2005). They make it possible to break a decisional problem (a root attribute) down into smaller, less complex subproblems represented by variables or attributes $\left(\mathrm{X}_{\mathrm{i}}\right.$, Fig. 2 ). These attributes are organized hierarchically so that those at higher levels of the hierarchy depend on those at lower levels. Attributes are aggregated through utility (or aggregation) functions $F$, which determine the dependence of a given attribute (called aggregate attribute) on its immediate descendants in the hierarchy (see example in Fig. 2). Options or alternatives to be evaluated are represented by a vector of values $\left(a_{i}\right)$ of attributes, called input attributes.

The aggregation procedure followed by DEX methodology is based on the hierarchical multi-attribute representation of decision problems used in many classical MAUT/MAVT models, but differs from this representation in a number of ways. MAUT/MAVT methods generally use (i) aggregation proce- dures based on multiplicative or additive formalisms that do not realistically capture the multidimensional nature of sustainability assessment and (ii) only quantitative information, hampering the use of empirical, non quantifiable knowledge that may be relevant for sustainability assessment (Munda et al., 1994; Munda, 2005). By contrast, DEX methodology is based on (i) qualitative (symbolic) attributes and (ii) utility functions based on 'If-Then' decision rules for the aggregation of these attributes. Such features make this approach highly suitable for realistic assessments of the sustainability of agricultural systems (Dent et al., 1995).

A DEX-based evaluation process follows the following pathway (Fig. 2):

(i) A vector of input attributes is identified and the decision problem is represented through a hierarchy of attributes;

(ii) Each attribute of the tree is scored on a qualitative scale (e.g., 'Low', 'Medium', 'High');

(iii) Decision rule-based utility functions are established for each aggregate attribute. In DEXi, a table is made available for users to enter qualitative values for aggregate attributes (e.g., Y, Fig. 2), as a function of the qualitative values of the attributes to be aggregated (e.g., $\mathrm{X}_{4}$, $\mathrm{X}_{5}$ and $\mathrm{X}_{6}$ ), thereby defining decision rules (e.g., IF $\mathrm{X}_{4}=$ 'medium' \& $\mathrm{X}_{5}=$ 'very low' \& $\mathrm{X}_{6}=$ 'low'; THEN $\mathrm{Y}=$ 'low'). Once the table is filled with these rules, the 


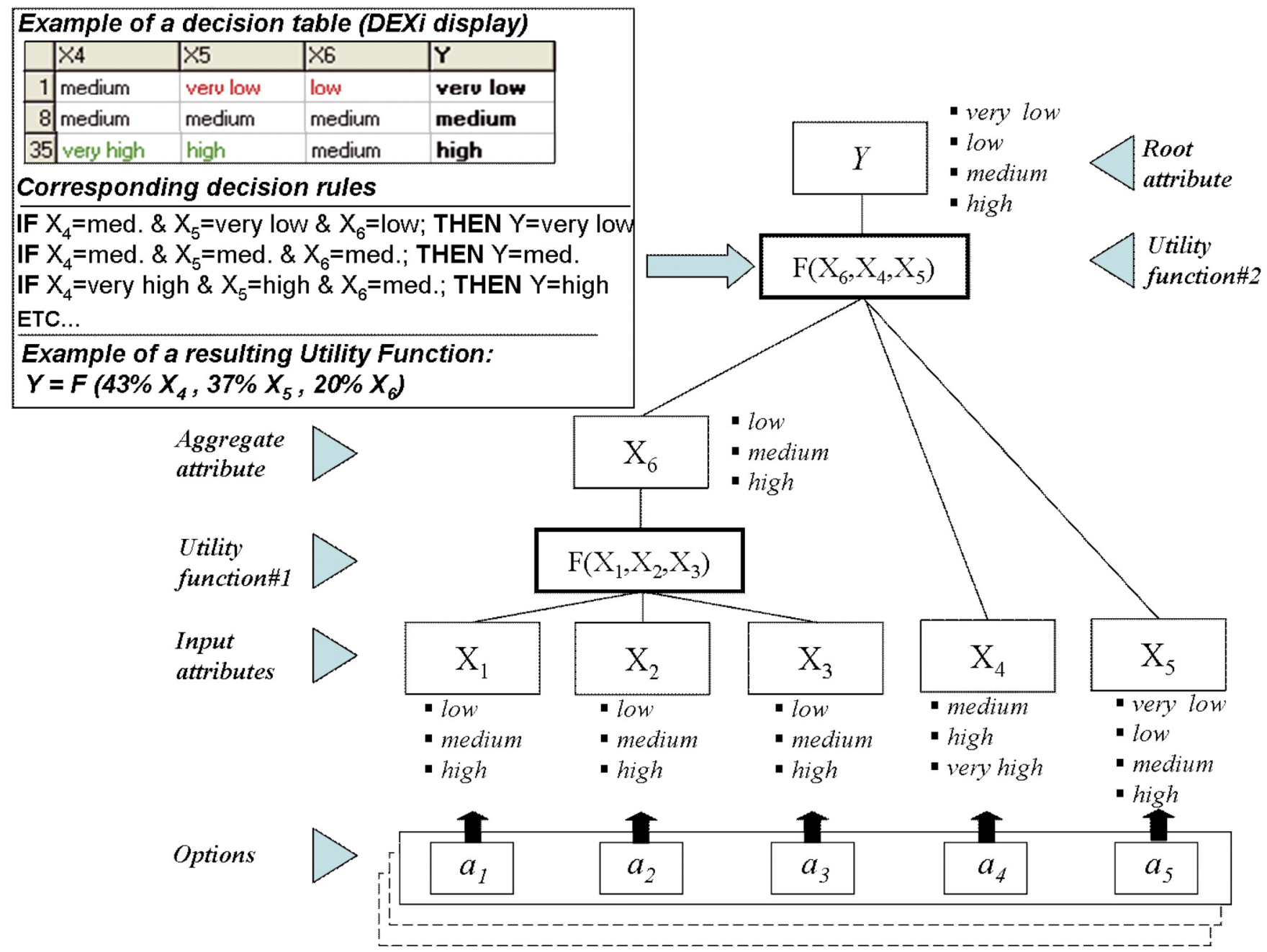

Figure 2. Typical structure and functioning of a decision rule-based, qualitative hierarchical multi-attribute model (adapted from Bohanec et al., 2000). The inset in the top left corner provides an example of the way in which a utility function is developed in the decision support system DEXi (see main text for details).

software provides users with a utility function representing a compilation of their choices expressed in terms of relative weightings (i.e., aggregation rules);

(iv) For the evaluation of an option, users enter the corresponding qualitative values of the input attributes and a qualitative result depending on the structure of the decision tree and the predefined utility functions is displayed (value of $\mathrm{Y}$ ).

In the DEXi decision support system, structures such as those shown in Figure 2 are dynamic, in that changing the qualitative value of a given attribute and/or modifying a few decision rules can have an immediate effect on the overall assessment. This approach makes it possible to carry out 'what-if' and 'selective explanation' and sensitivity analyses. In MASC, input attributes represent sustainability criteria and provide a qualitative rating of each cropping system (option). The aggregate attributes are represented by the various levels of sustainability assessment subproblems addressed by the decisional model. In its current version, the model structure, sustainability criteria and attribute scale structures are predefined. Aggregation rules are left open for definition by the user in $\approx 70 \%$ of cases (with suggested thresholds), for adaptation of the model to the climatic and agricultural context, with the remaining $30 \%$ predetermined on the basis of expert knowledge (Sect. 2.4.2). The qualitative rating of sustainability criteria is left to the decision-maker (with suggested guidelines, Sect. 2.4.1). The steps leading to the development of MASC are outlined in the section below.

\subsection{Workgroup organization and methodology}

The development of MASC and the first examples of its implementation result from the collaboration of a workgroup that functioned over two years according to the specific organizational and methodological procedures presented below. 


\subsubsection{Model development}

The development of DEX/DEXi-based models requires iteration of the following four steps: (i) attribute identification; (ii) attribute structuring; (iii) the definition of qualitative measurement scales for each attribute and (iv) the definition of aggregation rules. Typically, such models require collaboration between experts in the considered fields, who suggest attributes and aggregation rules, and decision analysts, who carry out the process and define a hierarchical structure for the attributes (Bohanec et al., 2008).

In our study, these four steps were carried out by eight agronomists. Each contributed his or her own expertise and, when necessary, exchanges took place with a pool of about 25 experts in research and development who took part in a previous program (Reau and Landé, 2006; Reau et al., 2006). Each of the eight agronomists also acted as a decision analyst, allowing the group to explore, compare and contrast different possible structures for the initial decision model and to identify the most consensual and relevant model. Input attributes were selected/developed by the workgroup on the basis of two main considerations:

(1) 'Thematic relevance', corresponding to the ability of the attributes to address realistically all the relevant issues underlying the assessment of sustainability at the scale of the cropping system. This goal was achieved by carrying out a specific literature review for each of the issues considered, to determine whether an indicator or methodology for its estimation had already been identified.

(2) 'Operational relevance', corresponding to the feasibility of implementing the chosen set of criteria in a multicriterion evaluation approach without biasing the assessment results. This goal was achieved by following the recommendations of Keeney and Raiffa (1976), Maystre et al. (1994) and Baker et al. (2002). We evaluated the extent to which the selected criteria were: (i) exhaustive and complete (i.e. including all goals), (ii) operational and meaningful in terms of the decision-maker's understanding of the implications of the assessment, (iii) able to discriminate between cropping systems, (iv) non redundant (as far as possible) and (v) realistically few enough in number to keep problem dimensions manageable.

\subsubsection{First examples of implementation}

The four cropping systems used to test the MASC model were initially developed based on the knowledge of 25 experts. One cropping system was designed to be representative of the cropping systems currently prevailing in Picardy/northern France (cropping system \#1), whereas the other three represented possible alternatives (cropping systems \#2, \#3 and \#4; Reau and Landé, 2006; Reau et al., 2006). The first MASCbased assessment process for these systems was carried out by the group of eight agronomists, acting as decision analysts.

\subsection{Features of the MASC model}

The overall structure of the MASC model is shown in Figure 3. It includes two interdependent components: (i) an input information processing unit (Fig. 3A) and (ii) a decision tree (Fig. 3B). These two components define a decision rule-based, qualitative multi-attribute model.

\subsubsection{Input information processing}

The input information (i.e., sustainability criteria) of the model is structured into a vector of 32 input attributes (Tab. I, Fig. 3). This vector was developed according to the working procedures described in Section 2.3. The vector had a heterogeneous initial informational structure, combining qualitative and quantitative information. The input information processing phase (i) calculates/estimates the values of the input attributes based on the corresponding methodology (Tab. I) and (ii) homogenizes the values by converting them all into qualitative (linguistic) variables, for processing by the decision tree (Fig. 3A).

\subsubsection{Initial calculation/estimation of the input attributes}

Table I summarizes the methods used to calculate the input attributes. All the calculations/estimations are carried out for each year of the rotation and averaged, except for one approach (I-Phy indicators, see below for details). During this phase, we distinguished between two main groups of attributes, based on the initial type of information (Fig. 3A).

The first group consisted of 15 input attributes initially estimated quantitatively, based on formalisms and models adapted from previous studies (e.g., economic attributes, Contribution to Local Employment, $\mathrm{NH}_{3}$ Emissions), or developed directly from expert knowledge (e.g., Phosphorus Use Autonomy, Sprayed Area, Tab. I).

Where necessary, formalisms and models from published studies were adapted to the scale of the cropping system. This was the case, for example, for economic attributes, such as Semi-Net Margin, which was adapted from the work of Dogliotti et al. (2004) for the estimation of cropping system profitability. Costs due to the storage, maintenance and repair of machinery, and infrastructure costs for buildings, roads and fences - which are not relevant at the cropping system scale - were not included in calculations of operating costs. Empirical quantitative models were developed, based on the expertise of the workgroup and the pool of consulted experts, if no satisfactory approach had been described in previous studies. This was the case for the attribute estimating the level of Phosphorus Use Autonomy of the cropping systems, as many studies have shown that phosphorus resources are not renewable and gradually decrease (Steen, 1998; Stewart et al., 2005).

The second group consisted of 17 input attributes initially estimated qualitatively, through two different approaches. The first approach involved the use of indicators readily giving 
B. Sustainability Evaluation: MASC Decision Tree

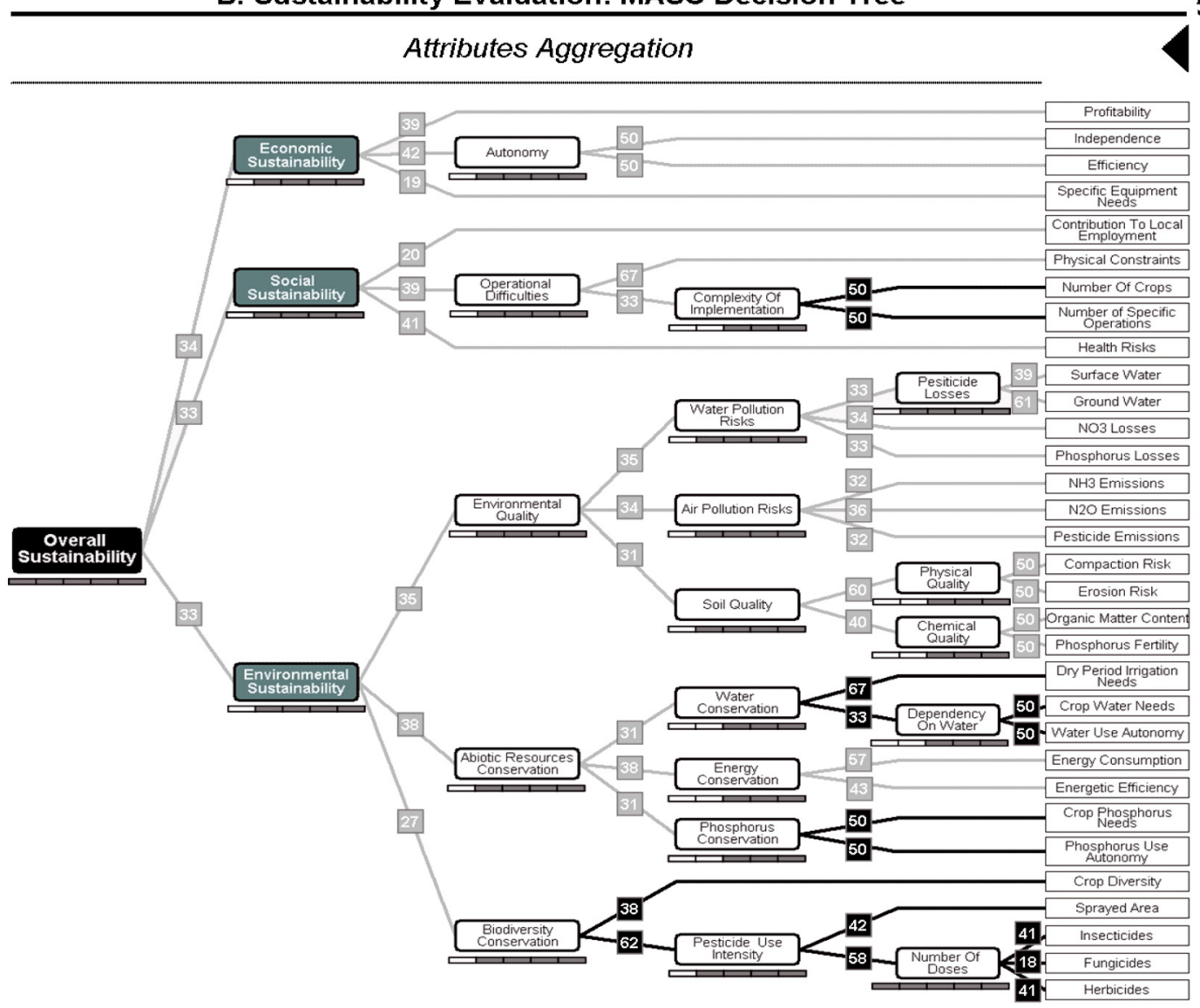

A. Input Processing Qualitative Initial Unit Scale 4 QL.QT.

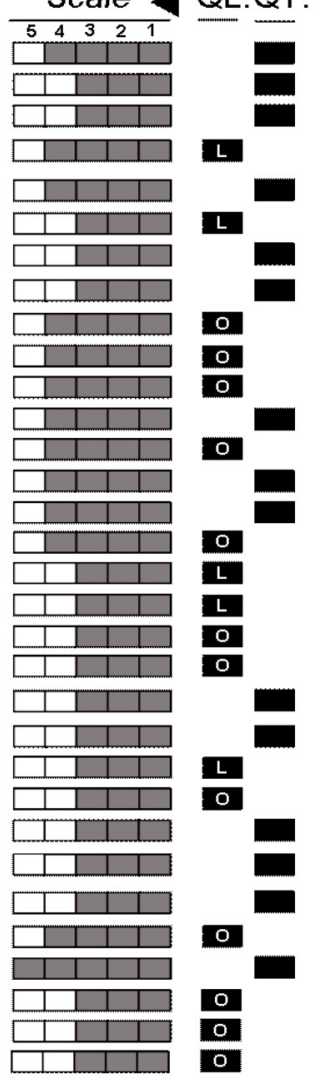

Figure 3. Sustainability criteria information processing and aggregation by the MASC decision tree, allowing ex ante assessment of the sustainability of cropping systems. A. After calculation/estimation (see Tab. I for details), initial units of the input attributes — either quantitative (QT, black rectangles) or qualitative (QL, black rectangles with L for 'linguistic' and O for 'ordinal') — are homogenized into linguistic values (e.g., 'Low', 'Medium', 'High') on 3- to 5-point scales (represented by the number of gray rectangles located to the right of the input attributes). B. The input attributes are then aggregated through levels of aggregate attributes (rounded rectangles), where the black and the three gray rectangles represent the overall and one-dimensional (economic, social or environmental) evaluation results, respectively. The aggregation rules are of two types: (i) totally free (thick gray lines) when aggregation is dependent on the specific context of the cropping system and on the knowledge and views of the decision-maker; and (ii) predetermined (thick black lines) when aggregation is independent of the context and depends instead on factual/expert knowledge (see details in the text). Numerical values in the decision tree displayed in gray and black boxes represent weightings corresponding to types (i) and (ii), respectively. They represent the aggregation rules used for the evaluation of four examples of cropping systems, the results of which are reported in Table II and Figure 4.

qualitative-ordinal scores (' $\mathrm{O}$ ' rectangles in Fig. 3A), including certain indicators from the I-Phy/INDIGO method (Bockstaller et al., 1997; Bockstaller and Girardin, 2006; e.g., Surface Water and Ground Water pesticide losses, soil Organic Matter Content, Energy Consumption), and those stemming from the treatment frequency index approach (Champeaux, 2006; e.g., Health Risks, number of doses for Insecticides/Fungicides/Herbicides). In this group, the inclusion of values for I-Phy indicators at the rotation scale was not directly based on averaging yearly values (as for all the other attributes), and the specific development of a 'satellite' decision tree (not shown) was required for calculation.

A second approach involves the development of bibliographic or expertise-based guidelines for the direct qualitative-linguistic estimation (e.g., 'Low', 'Medium', 'High') of attributes addressing issues for which no satisfactory quantitative or qualitative model could be identified in previous studies ('L' rectangles in Fig. 3A). This was the case, for example, for the Water Use Autonomy attribute, which estimates the extent to which water requirements depend on the main type of water supply to the cropping system.

\subsubsection{Qualitative transformation: scale and value choice}

Once calculated or estimated, the initial values of all input attributes are transformed into a qualitative-linguistic 
Table I. Summary of the different knowledge sources used as input attributes in MASC. ${ }^{1}$ Input attribute name (attribute order is the same as that reported in Fig. 3). ${ }^{2}$ Approaches used to calculate/estimate the input attributes. Quantitative formalisms are either described textually or mathematically when simple (e.g. water resource attributes and economic attributes, respectively) or referred to when too complex to fit in the table (e.g., some Indigo indicators, see corresponding references). Similarly, qualitative approaches are either described in text (when not based on specific formalisms) or referred to when based on published indicators. Calculations/estimations are made for each year of the rotation then averaged, except for I-Phy indicators (see text for details). Units are indicated when necessary. Units of qualitative attributes can be expressed on the basis of qualitative-ordinal scales (Indigo indicators) or qualitative-linguistic scales. ${ }^{3}$ References used. a: Dogliotti et al. (2004); b: Vilain et al. (2008); c: MSA (2006); d: Bockstaller et al. (1997), Bockstaller and Girardin (2006); e: Spoor et al. (2003), van de Zande (1991); f: Champeaux (2006); X: expertise. When necessary, imported formalisms were adapted to the scale of the cropping system (see text for details).

\begin{tabular}{|c|c|c|c|}
\hline Input Attribute $^{1}$ & \multicolumn{2}{|c|}{ Description / Calculation Method ${ }^{2}$} & Reference $^{3}$ \\
\hline \multirow[t]{3}{*}{ Profitability } & $\mathrm{SNM}=\mathrm{GP}-\mathrm{OC}$ & SNM: Semi-Net Margin $\left(€\right.$ ha $\left.^{-1}\right)$ & a \\
\hline & & GP: Gross Product $\left(€\right.$ ha $\left.^{-1}\right)$ & \\
\hline & & OC: Operational Costs $\left(€\right.$ ha $\left.^{-1}\right)$ & \\
\hline \multirow[t]{2}{*}{ Independence } & $E I=(1-D S / S N M) \times 100$ & El: Economic Independence (\%) & $\mathrm{b}$ \\
\hline & & DS: Direct Subsidies $\left(€\right.$ ha $\left.^{-1}\right)$ & \\
\hline Efficiency & $E E=(1-O C / G P) \times 100$ & EE: Ecomomic Efficiency (\%) & b \\
\hline Specific Equipment Needs & Qualitative estimation & & $x$ \\
\hline $\begin{array}{r}\text { Contribution To Local } \\
\text { Employment }\end{array}$ & NTW = EMWU $/ \mathrm{S}$ & $\begin{array}{l}\text { NTW: Number of temporary workers ha- } \\
\text { EMWU: Number of external man work units }\end{array}$ & $b$ \\
\hline Physical Constraints & \multicolumn{2}{|c|}{$\begin{array}{l}\text { Qualitative estimation based on: vibrations frequency, mouvements repetitiveness, frequency } \\
\text { of heavy loads manipulation, allergies, noise levels }\end{array}$} & c \\
\hline Number Of Crops & \multicolumn{2}{|c|}{ Indicator of implementation complexity } & $\mathrm{x}$ \\
\hline Number Of Specific Operations & \multicolumn{2}{|c|}{ Indicator of implementation complexity } & f \\
\hline Health Risks & \multicolumn{2}{|c|}{$\mathrm{TFI}_{\mathrm{Haz}}$ : Treatment Frequency Index calculated for hazardous products } & $x$ \\
\hline Surface Water & I-Phy $y_{\text {sw }}$ & Indigo Method (Qualitative/Ordinal score) & d \\
\hline Ground Water & I-Phy ${ }_{G W}$ & Indigo Method (Qualitative/Ordinal score) & d \\
\hline $\mathrm{NO}_{3}$ Losses & $\mathrm{I}-\mathrm{NO}_{3}$ & Indigo Method $\left(\mathrm{kg} \mathrm{NO}_{3}-\mathrm{N} \mathrm{ha}^{-1}\right)$ & d \\
\hline Phosphorus Losses & $I_{P}$ & Indigo Method (Qualitative/Ordinal score) & d \\
\hline $\mathrm{NH}_{3}$ Emissions & $\mathrm{I}_{\mathrm{NH}_{3}}$ & Indigo Method $\left(\mathrm{kg} \mathrm{NH}_{3}-\mathrm{N} \mathrm{ha}^{-1}\right)$ & $d$ \\
\hline $\mathrm{N}_{2} \mathrm{O}$ Emissions & $\mathrm{I}_{\mathrm{N}_{2} \mathrm{O}}$ & Indigo Method ( $\mathrm{kg} \mathrm{N}_{2} \mathrm{O}-\mathrm{N} \mathrm{ha}^{-1}$ ) & d \\
\hline Pesticide Emissions & I-Phy ${ }_{\text {air }}$ & Indigo Method (Qualitative/Ordinal score) & d \\
\hline Compaction Risk & \multirow{2}{*}{\multicolumn{2}{|c|}{$\begin{array}{l}\text { Qualitative estimation based on texture class, mechanization level, soil wetness, soil work type } \\
\text { Qualitative estimation based on soil water status, crusting sensitivity cover type, soil work type }\end{array}$}} & e \\
\hline Erosion Risk & & Qualitative estimation based on soil water status, crusting sensitivity, cover type, soil work type & $\mathrm{x}$ \\
\hline Organic Matter Content & $\mathrm{I}_{\mathrm{MO}}$ & Indigo Method (Qualitative/Ordinal score) & d \\
\hline Phosphorus Fertility & I Psoil $_{1}$ & Indigo Method (Qualitative/Ordinal score) & d \\
\hline Dry Period Irrigation Needs & \multicolumn{2}{|c|}{ Indicator of water resource conservation capacity (mm) } & $x$ \\
\hline Crop Water Needs & \multicolumn{2}{|c|}{ Indicator of water resource conservation capacity (mm) } & $x$ \\
\hline Water Use Autonomy & \multicolumn{2}{|c|}{ Qualitative estimation based on water supply type (rainfall, catchment basin, river, aquifer) } & $x$ \\
\hline Energy Consumption & $\mathrm{I}_{\text {Energy }}$ & Indigo Method (Qualitative/Ordinal score) & d \\
\hline Energetic Efficiency & $E N E=O E / I E \times 100$ & $\begin{array}{l}\text { ENE: Energetic Efficiency (\%) } \\
\text { OE: Output Energy (GJ) } \\
\text { IE: Input Energy (GJ) }\end{array}$ & $\mathrm{x}$ \\
\hline Crop Phosphorus Needs & \multicolumn{2}{|c|}{ Indicator of phosphorus resource conservation capacity ( $\mathrm{kg}$ of $\mathrm{P})$} & $x$ \\
\hline \multirow[t]{3}{*}{ Phosphorus Use Autonomy } & $A M P=(1-M P / T P) \times 100$ & $\begin{array}{l}\text { AMP: Autonomy with respect to Mineral Phosphorus (\%) } \\
\text { MP: Mineral Phosphorus }(\mathrm{kg}) \\
\text { TP: Total Phosphorus }(\mathrm{kg})\end{array}$ & $x$ \\
\hline & $\mathrm{I}_{\text {Div }}$ & Indigo Method (Qualitative/Ordinal score) & d \\
\hline & $\mathrm{PSA}=(1-\mathrm{NTC} / \mathrm{TCC}) \times 100$ & $\begin{array}{l}\text { PSA: Proportion of Sprayed Area (\%) } \\
\text { NTC: Number of non-Treated Crop Cycles } \\
\text { TCC: Number of Total Crop Cycles }\end{array}$ & $x$ \\
\hline Insecticides & $\left.\mathrm{TFI}\right|_{\text {Insecticides }}$ & TFI calculated for insecticides & f \\
\hline Fungicides & $\mathrm{TFI}_{\text {Fungicides }}$ & TFI calculated for fungicides & f \\
\hline Herbicides & $\mathrm{TFI}_{\text {Herbicides }}$ & TFI calculated for herbicides & $f$ \\
\hline
\end{tabular}


appreciation, using three- to five-value qualitative scales defined by the workgroup on the basis of expertise and depending on the resolution of the attribute (Fig. 3A). Typically, the linguistic scales take the form of a 'Low/Medium/High' progression, with the addition of 'Very Low' or 'Very High' in some cases, depending on the attribute (gray rectangles in Fig. 3A). The transformation process may be of one of two types, as a function of the initial type of transformation: (i) from quantitative to linguistic, (ii) from ordinal (qualitative) to linguistic. When the initial information is linguistic in nature, no transformation is needed (e.g., Physical Constraints, Compaction Risk, Water Use Autonomy, Tab. I, Fig. 3A). Suggestions as to the correspondence between initial information and linguistic scales are made in some cases, especially for some I-Phy/INDIGO indicators (e.g., Surface Water, Ground Water, Phosphorus Losses and Pesticide Emissions), which initially display ordinal outputs that must first be interpreted according to the score grid provided by the INDIGO framework (e.g., 0 to 10 for I-Phy, Tab. I), before transformation into linguistic information. In other cases, as for economic attributes (e.g., Profitability, Independence and Efficiency), interpretation of the quantitative results and their transformation into linguistic assertions are left to the decision-maker's discretion, because the interpretation process in these cases depends more on lo$\mathrm{cal} / \mathrm{specific}$ considerations and norms.

\subsubsection{The decision tree}

The MASC decision tree (Fig. 3B) is a hierarchical structure aggregating 32 input attributes through 22 aggregate attributes, based on 'If-Then' decision rules defining aggregation rules expressed as 'weightings' (details in Sect. 2.2 and Fig. 2), for assessment of the overall sustainability of cropping systems (Overall Sustainability attribute). The hierarchical structure shown in Figure 3B was developed from expert knowledge (according to the working process described in Sect. 2.3) and illustrates the decision-modeling process underlying the MASC model. As for input attributes, the scales for aggregate attributes are linguistic and defined on the basis of expert knowledge, with a resolution of three to five units (gray rectangles below aggregate attributes in Fig. 3). The aggregation process in MASC may be free or predetermined.

Free aggregation occurs in $\approx 70 \%$ of the cases in MASC (thick gray branches in Fig. 3B). In these cases, the model does not specify the strict weighting values to be assigned to the attributes to be aggregated (numbers in gray boxes refer to aggregation rules specific to the evaluation presented in Sect. 2.5). Instead, the choice is left open to the decisionmaker, so the aggregation of attributes depends on:

(i) Personal strategic views (e.g., aggregation of economic attributes or certain social attributes);

(ii) Local and specific environmental contexts and norms (e.g., aggregation within Water Pollution Risks submodel);

(iii) The decision-makers' broad representations of the sustainability assessment problem for their cropping systems, defining the priorities between (e.g., aggregation of economic, social and environmental sustainability) and within sustainability dimensions.

However, depending on the specific socioeconomic and environmental context of the cropping system to be assessed, it may be relevant to provide the decision-maker with expertisebased thresholds for the weightings to be used in the aggregation process. An example of this situation is provided in Section 2.5.

Predetermined aggregation is typical of the aggregations developed from expert knowledge by the workgroup, and may be considered valid regardless of the context and cropping system (Fig. 3B, thick black lines and numbers in black boxes). These aggregations define submodels (e.g. Water Conservation and Biodiversity Conservation submodels), which can be interpreted as 'synthetic indicators' processing input attributes and linking them with the decision tree.

\subsection{Specific settings for the first test of MASC}

Input information processing for these systems followed the steps described in Section 2.4.1. The aggregation rules followed for this specific assessment (numbers in gray boxes in Fig. 3B) were generated through interactions between the eight decision-makers/analysts of the workgroup.

The values used are offset from threshold aggregation rules, which were defined by the workgroup for most aggregations, by 15 to $33 \%$. In the absence of sensitivity analysis, the use of these settings ensured that the sustainability evaluation process was not distorted or biased by excessive weighting values (e.g. completely abolishing a sustainability component, using a weighting of 0 for one of the three main dimensions). These threshold values were established from expert knowledge, based on:

(i) Local considerations relating to the cropping systems (e.g. given the importance of soil quality problems in Picardy, minimum thresholds for Physical Quality and Chemical Quality attributes were set at $33 \%$ in the decision model) and

(ii) Considerations relating to the importance of different issues underlying sustainability in general (e.g. given the importance of the issues relating to the Environmental Quality, Abiotic Resources Conservation and Biodiversity Conservation attributes, the minimum threshold value for aggregation was set at $20 \%$ for each of these attributes). A similar rationale could be applied to the aggregation of economic, social and environmental sustainability submodels, for which minimum aggregation thresholds were set at $15 \%$.

\section{RESULTS AND DISCUSSION}

\subsection{First test of MASC: implication for future real-case studies}

The coherence of the MASC model was tested by assessing four cropping systems generated from expert knowledge 
(see Sect. 2.3), through the specific steps described above. The initial qualitative values of the input attributes, together with those relating to all the aggregate attributes resulting from combinations of these initial values, are given in Table II, with the aggregation rules followed for this assessment reported in Figure 3B (numbers in gray and black boxes).

A detailed interpretation of the results obtained would not be relevant in this study because the cropping systems used here were developed for testing the model, rather than for a real comparison of sustainability. Nonetheless, the evaluation results were consistent with the initial representation of the cropping systems: as expected, the prevailing cropping system (CS\#1) displayed high economic sustainability and low environmental sustainability, and the 3 alternative cropping systems developed on the basis of expertise (CS\#2, CS\#3 and CS\#4, Fig. 4) had higher values for environmental and overall sustainability, ranging from 'Medium' to 'Very High'. The decision rules used did not generate 'illogical' outputs, at least for this test, which provides a first approximation of the coherence of the logic behind the disaggregation-aggregation approach in MASC. This outcome paves the way for a more formal assessment of realistic cases.

\subsection{Relevance of the holistic representation of the sustainability concept at the cropping system scale}

MASC explicitly and specifically functions at the scale of the cropping system, and this is an important characteristic. The cropping system scale has a granularity intermediate between those of the single plot/single year and farming system scales. The use of this scale makes it possible to isolate the effects on overall socioeconomic and environmental performance of different cropping activities within a farming system, and to take interactions between individual crops in the process into account in an explicit manner.

A second key feature of MASC is that it explicitly formalizes a global concept of sustainability, discretized and encapsulated into a vector of 32 input criteria (Fig. 3, Tab. I). Although MASC addresses the relatively limited scale of the cropping system, a critical objective of this study was to make this model as holistic as reasonably possible, by addressing issues not classically addressed at this scale but considered by a growing number of researchers to be 'challenging targets for future agriculture' (see Kirchmann and Thorvaldsson, 2000 for review). MASC may therefore be considered a "standalone" tool, which is not the case for other models analyzed in similar studies assessing cropping systems. Indeed, comparable studies have either targeted (i) specific objectives underlying sustainability, such as the impact of cropping systems on soil quality (Bohanec et al., 2007), and the economic and ecological impacts of genetically modified crops (Bt maize; Bohanec et al., 2008) or (ii) overall sustainability, but through a limited number of sustainability criteria, as in the study by Mazzetto and Bonera (2003), who considered 9 criteria encompassing economic, environmental and technical issues to be aggregated within a specifically designed sustainability assessment tool.

Classically, studies addressing sustainability assessment at larger scales, such as farming systems, benefit from a larger number of input criteria (e.g., frameworks of Phillis and Andriantiatsaholiniainan, 2001; Häni et al., 2003; Van Cauwenbergh et al., 2007; Meul et al., 2008). Thus, for the specific needs of the MASC, we either (i) directly 'imported' criteria generally considered at higher levels or (ii) simply generated our specific criteria as a function of the issues targeted, based on a combination of literature review and expert knowledge.

Criteria were directly imported, for example, for certain economic sustainability factors considered by MASC. This was the case for the set of attributes reflecting economic independence and efficiency, which were imported from the IDEA framework (Vilain et al., 2008), to reflect medium-term economic sustainability objectives (in addition to short-term profitability, Fig. 3, Tab. I).

Specific criteria were generated in cases in which no readyto-use indicators were available at cropping-system scale. This was the case for the 'synthetic indicators' of MASC (see Sect. 2.4.2), represented by the submodels aggregated on the basis of expert knowledge for both social (Complexity of Implementation) and environmental (Water Conservation, Phosphorus Conservation and Biodiversity Conservation) sustainability dimensions.

Classically, the social sustainability dimension is either not represented (Bohanec et al., 2008) or only implicitly considered in studies targeting cropping systems (e.g., 'operating difficulty' criterion as a part of a technical evaluation, Mazzetto and Bonera, 2003). In MASC, we chose to address this issue more explicitly, by developing an indicator dealing with the Complexity of implementation in the context of the worker's quality of life and, thus, as a component of the social sustainability of the cropping system. Furthermore, in line with the recommendations of Calker et al. (2007), we explicitly considered the health of agricultural workers in our assessment. Two complementary standpoints, each represented by a sustainability criterion, were used for this analysis: the actual constraints experienced by the worker, based on an interpretation grid provided by the MSA (Mutualité Sociale Agricole, 2006, Tab. I) and risks due to contact with hazardous substances.

For the Water Conservation attribute, we focused on water consumption as a function of local critical periods and the type of water supply, rather than on absolute water consumption values or water use efficiency-based factors, as the principal aim was to estimate the local impact of the cropping system on the availability of water as an increasingly rare (and shared) resource. Similar approaches were followed in the RISE (Häni et al., 2003) and MOTIFS (Meul et al., 2008) sustainability assessment frameworks, although neither of these models explicitly took into account the occurrence of critical periods of water shortage, which are becoming increasingly frequent in many temperate areas of Europe, and elsewhere. The same type of reasoning was applied to Phosphorus Conservation. Phosphorus use is taken into account in many sustainability assessment frameworks, mostly in terms of losses, use efficiency 
Table II. Detailed results of the sustainability assessment carried out with MASC for four cropping systems generated from expert knowledge. ${ }^{a}$ Compacted hierarchical representation of the decision tree shown in Figure 3B. The root attributes of the whole model (Overall Sustainability) and those of the Economic, Social and Environmental submodels are represented with black and gray backgrounds, respectively. Aggregate attributes are presented in bold typeface. The number of points preceding the name of each attribute indicates its hierarchical distance from the root attribute. ${ }^{b}$ Qualitative values of all the attributes of the MASC model, for each assessment. The scales from which the qualitative values of each attribute were taken are reported in Figure 3 (gray rectangles to the right of and below input and aggregate attributes, respectively). Bold qualitative values are those resulting from aggregation, according to the values of descendents and the predefined aggregation rules (numbers in gray and black boxes in Figure 3B). ${ }^{\text {b1 }}$ Cropping system (CS), inspired from actual systems in Picardy (northern France), described in the "ADAR Systèmes de cultures innovants" project. ${ }^{\text {b2 }}$ Three alternative systems described in the "ADAR Systèmes de culture innovants" project.

\begin{tabular}{|c|c|c|c|c|}
\hline \multirow{3}{*}{ Attributes Hierarchy ${ }^{a}$} & \multicolumn{4}{|c|}{ Attribute values and Assessment results ${ }^{b}$} \\
\hline & \multirow{2}{*}{$\frac{\text { Actual }^{\text {b1 }}}{\text { CS\#1 }}$} & \multicolumn{3}{|c|}{ Alternatives $^{\mathrm{b} 2}$} \\
\hline & & CS\#2 & CS\#3 & CS\#4 \\
\hline Overall Sustainability & Low & High & Very High & Medium \\
\hline Economic Sustainability & Very High & Very High & Very High & Very High \\
\hline . Profitability & Medium & High & High & High \\
\hline . A Autonomy & Medium & Very High & Medium & Medium \\
\hline ... Independence & Medium & High & Medium & Medium \\
\hline ... Efficiency & Medium & High & Medium & Medium \\
\hline . . Specific Equipment Needs & Low & Medium & Medium & Low \\
\hline Social Sustainability & Low & Very High & Very High & Low \\
\hline . . Contribution To Local Employment & Medium & Very High & Very High & Medium \\
\hline . Operational Difficulties & Medium & Low & Low & Low \\
\hline ... Physical Constraints & High & Low & Medium & Medium \\
\hline . . Complexity Of Implementation & Low & High & High & Medium \\
\hline$\ldots$ Number Of Crops & Low & High & High & Medium \\
\hline . . . Number of Specific Operations & Low & Medium & Medium & Medium \\
\hline .. Health Risks & High & Very Low & Low & Medium \\
\hline . Environmental Sustainability & Low & Medium & Very High & Medium \\
\hline . . Environmental Quality & Very Low & Low & Medium & Low \\
\hline . . . Water Pollution Risks & Medium & Low & Low & Medium \\
\hline . . . Pesiticide Losses & Low & Very Low & Low & Low \\
\hline . . . . Surface Water & Low & Low & Low & Low \\
\hline . . . . Ground Water & Medium & Low & Medium & Medium \\
\hline . . . NO3 Losses & Low & Low & Very Low & Medium \\
\hline .... Phosphorus Losses & Medium & Medium & Low & Medium \\
\hline . . A Air Pollution Risks & Medium & Low & Low & Low \\
\hline . . . NH3 Emissions & Very High & Low & Medium & Low \\
\hline . . . N2O Emissions & Medium & Medium & Medium & Medium \\
\hline .... Pesticide Emissions & Medium & Low & Low & Medium \\
\hline ... Soil Quality & Low & Low & Medium & High \\
\hline ... . Physical Quality & Medium & Medium & Medium & High \\
\hline ... . . Compaction Risk & Low & Medium & Low & Medium \\
\hline .... . Erosion Risk & Medium & Medium & Medium & Low \\
\hline ... . Chemical Quality & Low & Low & Medium & High \\
\hline .... . Organic Matter Content & Medium & Medium & Medium & Medium \\
\hline .....Phosphorus Fertility & Very Low & Very Low & Low & Medium \\
\hline . Abiotic Resources Conservation & Low & Medium & Medium & Medium \\
\hline ... Water Conservation & Medium & Medium & Low & Medium \\
\hline ... . Dry Period Irrigation Needs & Medium & Medium & High & Medium \\
\hline ... . Dependency On Water & Medium & Medium & Medium & Medium \\
\hline .... . Crop Water Needs & Medium & Medium & High & Medium \\
\hline . . . . Water Use Autonomy & Medium & Medium & High & Medium \\
\hline ... Energy Conservation & Low & High & High & High \\
\hline .... Energy Consumption & Medium & Low & Low & Low \\
\hline ... Energetic Efficiency & Low & High & High & Medium \\
\hline ... Phosphorus Conservation & High & High & High & High \\
\hline ... . Crop Phosphorus Needs & Medium & Medium & Medium & Medium \\
\hline ... . Phosphorus Use Autonomy & High & High & High & High \\
\hline . Biodiversity Conservation & Very Low & High & High & Medium \\
\hline ... Crop Diversity & Low & High & High & Medium \\
\hline . . Pesticide Use Intensity & Very High & Low & Low & Medium \\
\hline ... . Sprayed Area & High & Very Low & Low & Medium \\
\hline .... Number Of Doses & High & Very Low & Very Low & Medium \\
\hline$\ldots$. Insecticides & Medium & Low & Low & Medium \\
\hline ..... Fungicides & Medium & Low & Medium & Low \\
\hline ..... Herbicides & High & Low & Low & Medium \\
\hline
\end{tabular}




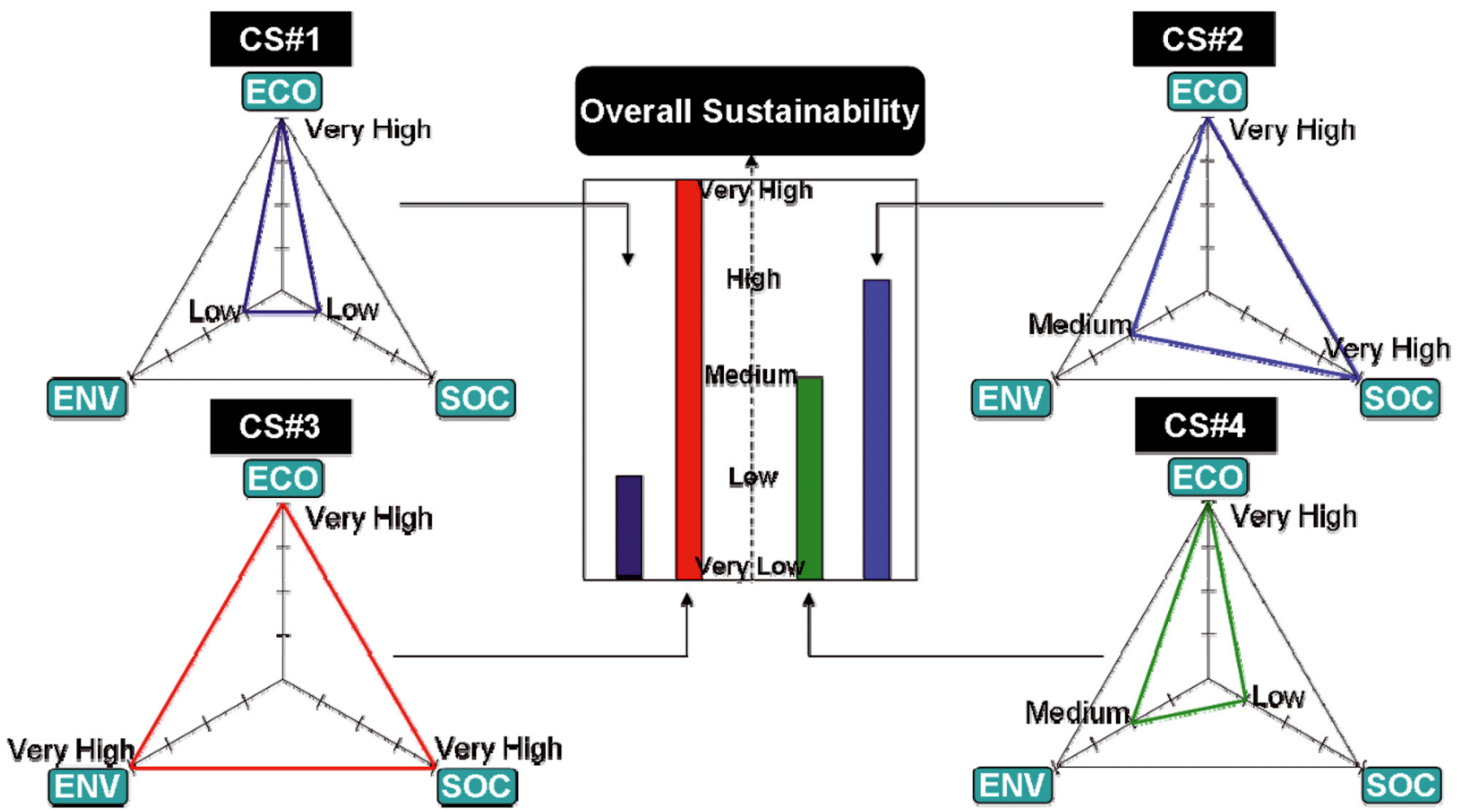

Figure 4. Graphical representation of the results of the sustainability assessment carried out in MASC for four cropping systems generated from expert knowledge. Radar plots represent the evaluation results for each of the three sustainability dimensions considered by the model, where ECO, SOC and ENV refer to the economic, social and environmental sustainability assessment submodels, respectively. CS\#1 to CS\#4 refer to cropping systems \#1 to \#4, respectively. The overall sustainability evaluation results for each cropping system are reported in the central bar graph, with the qualitative scales inserted in the middle. Each color refers to the corresponding cropping system. Details of the (i) qualitative values of both input and aggregate attributes and (ii) aggregation rules corresponding to these results are reported in Table II and Figure 4, respectively.

or soil fertility (Häni et al., 2003; Dogliotti et al., 2004; Meul et al., 2008), but few, if any, of these studies considered phosphorus use explicitly from this 'rarefaction' standpoint, so the importation of pre-existing indicators was not successful.

For Biodiversity Conservation, previous studies have reported a plethora of biodiversity indicators for measuring the impact of agricultural systems on surrounding ecological niches, but these indicators are designed for use with much larger scales, such as landscapes and regions (Osinski et al., 2003; Hietala-Koivu et al., 2004). Many of these indicators are actually 'bioindicators' measuring the impact on population dynamic parameters of specific groups or taxa of animals (mainly insects) and plants (Paoletti, 1999; Döring et al., 2003; Parisi et al., 2005). We felt that it was irrelevant to approach biodiversity assessment ex ante and at the limited scale of the cropping system from the bioindicator standpoint, because (i) this approach may be cumbersome (Braband et al., 2003) and (ii) a given bioindicator may be valid in one context but not in another. We therefore used an approach based on indirect estimation of the impact of the cropping system on biodiversity conservation, considering Pesticide Use Intensity to be representative of a 'pressure' component and Crop Diversity, which is assumed to be positively correlated with biodiversity conservation in many assessment frameworks (see Braband et al., 2003 for review).
Overall, the resulting vector of 32 sustainability criteria may be considered to give an unbalanced representation of the three dimensions of sustainability, in that economic and social criteria are outnumbered by environmental criteria. However, this is not specific to the MASC model, as a similar 'imbalance' is observed in most sustainability assessment-dedicated frameworks, functioning at different levels of agricultural systems. This situation may result from the monetary nature of economic criteria, rendering these criteria less holistic than environmental criteria, which cover a large variety of complex and intricate problems. Social criteria occupy an intermediate position, as more considerations, such as landscape quality, animal well-being, food security and safety and community function, may be taken into account, depending on the scale at which the assessment is carried out.

\subsection{Sustainability assessment modeling by MASC: advantages and restrictions}

\subsubsection{Advantages}

\subsubsection{Underlying MCDA methodology}

A functional key feature of MASC lies in its underlying MCDA methodology. This methodology was selected in 
accordance with the recommendations we issued in a previous paper (Sadok et al., 2008) for identifying relevant tools for the ex ante assessment of cropping systems. The functional value of MASC lies partly in its implementation within a DSS (decision support system) using a 'mixed' (or non-classical) MCDA method for the explicit handling of qualitative information and the expression of preferential information through qualitative decision rules aggregating initial criteria. Such features are not common within the large group of MCDA tools used for sustainability assessment of agricultural systems (i.e., Häni et al., 2003; Dogliotti et al., 2005; MeyerAurich, 2005; Van Cauwenbergh et al., 2007; Meul et al., 2008). Explicitly qualitative information can capture the uncertainties inherent to sustainability assessment (especially in the ex ante mode) and more realistically integrate the decisionmaker's own views, as they are not necessarily expressed through formal, quantitative models (Dent et al., 1995; Munda, 2005). In addition, the method used here handles incomparability, incommensurability and non compensation between sustainability dimensions (see review by Sadok et al., 2008) more efficiently than other more 'classical' MCDA approaches frequently used for sustainability assessment, such as ELECTRE (Loyce et al., 2002; Mazzetto and Bonera, 2003), AHP (Shrestha et al., 2004) or multi-objective optimization tools (Dogliotti et al., 2005; Meyer-Aurich, 2005).

\subsubsection{Representation of the sustainability assessment problem}

In terms of decision modeling, one of the specific features of MASC is the way in which it conceptualizes the sustainability assessment problem (Fig. 3). During the development of this model, it was decided that this representation should not follow a cause-effect modeling approach (i.e., relationships between the properties of the cropping system and their impacts). The representation of these relationships would have been highly cumbersome, given the high level of interdependency between the economic, social and environmental dimensions. We therefore used a decisional approach to break the assessment problem down. This approach was based on an interpretation of a frequently used definition of 'sustainability' (three dimensions, each representing a hierarchy of sustainability objectives), making the assessment much more manageable. This approach has two major advantages.

The first is an 'operational' advantage, resulting from the compromise between the maintenance of realistic representations of the sustainability assessment decisional problem and limiting the number of decision rules implemented. This compromise keeps the decisional problem to a manageable size, as recommended by $\mathrm{Ma}$ (2006). It resulted in the MASC model having far fewer decision rules than the model used by Bohanec et al. (2008), which addressed the specific problem of the ecological and economic assessment of cropping systems based on genetically modified crops and developed on the basis of the same MCDA methodology.

The second advantage is the potential 'pedagogical' value of MASC. Pedagogical value is not generally considered essential in sustainability assessment frameworks, in which preference models are partly or totally opaque to the users. The software version of MASC (MASC_V1.0, implemented within the DSS tool DEXi) provides a graphical and dynamic representation of the whole hierarchy, from the input criteria to the root attribute, making it possible for users to trace the effects of changes in the value of a single criterion on the overall result of the assessment. This feature is particularly relevant in cases in which the decision-maker is unaware of many of the implications of sustainability at the cropping system scale, which is more often the case for non specialists. This pedagogical value is enhanced by the need for users to specify the weightings to be applied to different dimensions and the underlying objectives, as a function of their own contexts and priorities, requiring them to supply their own definition of sustainability. In addition, the use of qualitative information at all levels of the model (input attributes, If-Then decision rules) probably makes this model more accessible to a wider range of decision-makers than more mechanistic, quantitative models, as qualitative models are able to represent more realistically empirical knowledge resulting from personal views and experiences.

\subsubsection{Restrictions on the use of MASC}

\subsubsection{Qualitative modeling limitations}

The exclusive use of qualitative input information by MASC inevitably limits its resolution, as quantitative data cannot be used directly. Moreover, the use of qualitative data requires greater attention in the description of the hypotheses adopted and of the procedure used to develop criteria, because qualitative data are more difficult to interpret objectively than quantitative data (Andreoli et al., 1999). This is particularly the case for the transformation into qualitative (linguistic) values for certain input quantitative attributes of MASC. There is a risk that the link between the 'absolute' quantitative value and the 'chosen' qualitative scale is not unique and depends on the decision-maker. However, this situation may also render the tool more flexible, as, for example, a semi-net margin of $700 € /$ ha may be translated into different qualitative values (e.g., 'Low', 'Medium', 'High') depending on the decision-maker's opinion and the context. A balance between limitation and flexibility must therefore be reached. MASC (MASC_V1.0) software includes a tutorial, with guidelines for the quantitative-qualitative transformation for each input attribute.

In addition, the fact that the models implemented with the DEXi DSS are based on 'If-Then' decision rules - which can define only relationships between conditions and consequences - hampers the modeling of the intrinsic proprieties and functioning of the systems considered (Bohanec et al., 2008). This makes it difficult to investigate the intrinsic sources of differences between the cropping systems assessed, unless the approach is combined with quantitative, mechanistic models (e.g., crop models, management plans, etc.). This was not a critical limitation in this study, because MASC aims 
to compare cropping systems on the basis of their impact on sustainability, rather than to identify the sources of differences between the alternatives. It would probably be more relevant to consider this aspect at the cropping system generation phase of the framework.

\subsubsection{Sustainability assessment limitations}

Assessments of holistic entities, such as sustainability particularly from an ex ante perspective - inevitably result in significant uncertainty. According to Walter (2006), this uncertainty is threefold: (i) social and technological, because needs and priorities are continually changing, (ii) epistemic, due to inevitable gaps in the knowledge representing economic, social and environmental systems and (iii) stochastic, due to random, unpredictable phenomena in both natural (e.g., climatic) and social systems (e.g., economic crisis).

Since the early stages of development of the MASC model, it has been clear that one of the principal weaknesses of this model lies in its not taking these uncertainties into account in an explicit manner. We feel that this criticism could also be leveled at most sustainability assessment frameworks. However, MASC provides opportunities to handle the first two types of uncertainty, at least to some extent, through (i) the flexibility it offers the user in terms of the choice of aggregation rules ( $70 \%$ of which are left open to the decision-maker) and (ii) the use of qualitative modeling to deal with the inevitable lack of quantitative knowledge for some issues underlying sustainability assessment for cropping systems. For stochastic uncertainties, the sensitivity of the sustainability of a cropping system to a 'stochastic' event could be assessed by including this variation in the calculation/estimation of all criteria rather than in the decision model itself. This would make it possible to compare different assessment results for the same cropping system subjected to different sets of environmental/socioeconomic conditions. In this context, it might be possible to connect the formalism underlying the input attributes to the databases generating scenarios. An approach of this kind is already planned in the framework of sensitivity analysis for the decision model.

\section{CONCLUSION}

The model described here is the first version of a registered tool, $M A S C_{-} V 1.0$, a key element of an ex ante (i.e., 'Beforethe-event') assessment framework for use at cropping system level. Such tools are designed to assess the sustainability of different cropping systems before their implementation in the field. This approach is potentially of prime importance in a world in which the economic, social and environmental constraints and objectives shaping sustainability change so rapidly that the window for classical in-field prototyping approaches is very small.

The key features of this tool are its (i) scale of assessment; it explicitly considers the cropping system level, which is viewed as the basic functional unit making up a farming system, (ii) unique vector of 32 input criteria across the three dimensions of sustainability spanning a wide spectrum of sustainability objectives, (iii) the use of a 'mixed', alternative MCDA method able to handle qualitative information and to express preferential information through qualitative If-Then decision rules, which are easy to handle by non specialists and (iv) its transparent and dynamic decision model, providing a formal definition of sustainability helping decision-makers to understand the implications of their views, experiences and decisions for the overall sustainability of their system. The implementation test presented here should be seen as the first of a series of tests, culminating in the production of version 1.1 of the tool.

A detailed analysis of the sensitivity of MASC is already underway. This study should make it possible to estimate the granularity offered by this tool for different decisional (i.e., aggregation rules) and cropping system representation (i.e., input attribute values) scenarios, taking into account pedoclimatic and socioeconomic fluctuations. This work may lead to adjustments to the definition of scales and aggregation rules in MASC.

Another short-term perspective concerns testing of the generic nature of the model for a large range of cropping systems and types of decision-makers. Such testing is also already underway because MASC is currently available to various groups. We expect it to be necessary to make some adjustments to the model, the most significant of these changes occurring at the input attribute level. However, the current version of MASC is flexible as to the choice of formalism underlying its input attributes, as we feel it is more appropriate to allow the replacement of certain formalisms by others more in line with the decision-maker's own views, context or cropping system type. This flexibility has already been used in the development of a variant of the MASC model for the assessment of dairy grazing systems (Coquil et al., 2007).

In the medium term, we plan to use a more formalized approach for generating the cropping systems to be assessed ex ante. This requires the development of an explicit generation module based on simulation tools (Bergez et al., 2008) or combinatory approaches (Dogliotti et al., 2003). We are also considering the possibility of developing an expert system in the DSS in which MASC is implemented, as a tool for generating cropping systems.

Acknowledgements: This study was funded by the ANR (Agence Nationale de la Recherche) under the French Federator Program ADD (Agriculture et Développement Durable) via the DISCOTECH (DISpositifs Innovants pour la COnception et l'évaluation des systèmes TECHniques) Project. We thank Marko Bohanec for providing us with the latest version of DEXi and its documentation. We also thank the group of 25 experts from the "ADAR Systèmes de culture innovants" project, including Nathalie Landé (CETIOM) in particular.

\section{REFERENCES}

Andreoli M., Rossi R., Tellarini V. (1999) Farm sustainability assessment: some procedural issues, Landscape Urban Plan. 46, 41-50.

Baker D., Bridges D., Hunter R., Johnson G., Krupa J., Murphy J., Sorenson K. (2002) Guidebook to Decision-Making Methods, WSRC-IM-2002-00002, Department of Energy, USA. 
Bergez J.E., Colbach N., Crespo O., Garcia F., Jeuffroy M.H., Justes E., Loyce C., Munier-Jolain N., Sadok W. (2008) Designing crop management systems by simulation, in: Donatelli M., Hatfield J., Rizzoli A. (Eds.), Farming Systems Design 2007, Int. Symposium on Methodologies on Integrated Analysis on Farm Production Systems, Catania (Italy), 10-12 September 2007, book 2 - Fieldfarm scale design and improvement, pp. 4-5.

Bockstaller C., Girardin P. (2006) Mode de calcul des indicateurs agrienvironnementaux de la méthode INDIGO (Version $1.61 \mathrm{du}$ logiciel), INRA COLMAR/ARAA.

Bockstaller C., Girardin P., van der Werf H.M.G. (1997) Use of agroecological indicators for the evaluation of farming systems, Eur. J. Agron. 7, 261-270.

Bohanec M. (2003) Decision support, in: Mladeniæ D., Lavraè N., Bohanec M., Moyle S. (Eds.), Data mining and decision support: Integration and collaboration, Kluwer Academic Publishers, pp. 23-35.

Bohanec M., Cortet J., Griffiths B., Znidarsic M., Debeljak M., Caul S., Thompson J., Krogh P.H. (2007) A qualitative multi-attribute model for assessing the impact of cropping systems on soil quality, Pedobiologia 51, 239-250.

Bohanec M., Messéan M., Scatasta S., Angevin F., Griffiths B., Krogh P.H., Znidarsic M., Dzeroski S. (2008) A qualitative multi-attribute model for economic and ecological assessment of genetically modified crops, Ecol. Model. (in press), doi:10.1016/j.ecolmodel.2008.02.016.

Bohanec M., Zupan B., Rajkovic V. (2000) Applications of qualitative multi attribute decision models in health care, Int. J. Med. Informat. 58-59, 191-205.

Braband D., Geier U., Köpke U. (2003) Bio-resource evaluation within agri-environmental assessment tools in different European countries, Agr. Ecosyst. Environ. 98, 423-434.

Calker K.J. van, Berentsen P.B.M., Boer I.J.M. de, Giesen G.W.J, Huirne R.B.M. (2007) Modelling worker physical health and societal sustainability at farm level: an application to conventional and organic dairy farming, Agr. Syst. 94, 205-219.

Champeaux C. (2006) Recours à l'utilisation de pesticides en grandes cultures : évolution de l'indicateur de fréquence de traitements au travers des enquêtes "pratiques culturales" du SCEES entre 1994 et 2001. INRA, UMR d'Agronomie de Grignon, rapport d'étude commanditée par le MAP (DGFAR), 100 p.

Christen O. (1998) No more definitions please! Some reflections about the ideas and principles of sustainable agriculture, in: El Bassam N., Behl R.K., Prochnow B. (Eds.), Sustainable Agriculture for Food, Energy and Industry, James \& James, London, pp. 48-52.

Clemen R.T. (1996) Making Hard Decisions: an Introduction to Decision Analysis, Wadsworth Publishing Company.

Coquil X., Blouet B., Fiorelli J.L., Mignolet C., Bazard C., Foissy D., Trommenschlager J.M., Benoît M., Meynard J.M. (2007) Prototyping connected farming systems at a small territory scale, in: Donatelli M., Hatfield J., Rizzoli A. (Eds.), Farming Systems Design 2007, Int. Symposium on Methodologies on Integrated Analysis on Farm Production Systems, Catania (Italy), 10-12 September 2007, book 2 - Field-farm scale design and improvement, pp. 120-121.

den Biggelaar C., Suvedi M. (2000) Farmers' definitions, goals, and bottlenecks of sustainable agriculture in the North-Central Region, Agr. Hum. Val. 17, 347-358.

Dent J.B., Edward-Jones G., McGregor M.J. (1995) Simulation of ecological, social, and economic factors in agricultural systems, Agr. Syst. 49, 337-351.
Dogliotti S., Rossing W.A.H., Van Ittersum M.K. (2003) ROTAT, a tool for systematically generating crop rotations, Eur. J. Agron. 19, 239250.

Dogliotti S., Rossing W.A.H., Van Ittersum M.K. (2004) Systematic design and evaluation of crop rotations enhancing soil conservation, soil fertility and farm income: a case study for vegetable farms in South Uruguay, Agr. Syst. 80, 277-302.

Dogliotti S., Van Ittersum M.K., Rossing W.A.H. (2005) A method for exploring sustainable development options at farm scale: a case study for vegetable farms in South Uruguay, Agr. Syst. 86, 29-51.

Döring T.F., Hiller A., Wehke S., Schulte G., Broll G. (2003) Biotic indicators of carabid species richness on organically and conventionally managed arable fields, Agr. Ecosyst. Environ. 98, 133-139.

Espinosa A., Harnden R., Walker J. (2008) A complexity approach to sustainability - Stafford Beer revisited, Eur. J. Oper. Res. 187, 636651.

European Commission (2005) Impact Assessment Guidelines, 15th of June 2005 with March 2006 Update, SEC (2005) 791.

Figueira J., Greco S., Ehrgott M. (2005) Multiple Criteria Decision Analysis: State of the Art Surveys, Springer-Verlag, New York.

Gafsi M., Legagneux B., Nguyen G., Robin P. (2006) Towards sustainable farming systems: Effectiveness and deficiency of the French procedure of sustainable agriculture, Agr. Syst. 90, 226-242.

Häni F., Braga F., Stämpfli A., Keller T., Fischer M., Porsche H. (2003) RISE, a tool for holistic sustainability assessment at the farm level, Int. Food Agribus. Manag. Rev. 6, 78-90.

Hansen J.W. (1996) Is agricultural sustainability a useful concept? Agr. Syst. 50, 117-143.

Hietala-Koivu R., Järvenpää T., Helenius J. (2004) Value of semi-natural areas as biodiversity indicators in agricultural landscapes, Agr. Ecosyst. Environ. 101, 9-19.

Keeney R., Raiffa H. (1976) Decisions with Multiple Objectives: Performances and Value Trade-Offs, Wiley, New York.

Kirchmann H., Thorvaldsson G. (2000) Challenging targets for future agriculture, Eur. J. Agron. 12, 145-161.

Lançon J., Reau R., Cariolle M., Munier-Jolain N., Omon B., Petit M.-S., Viaux P., Wery J. (2008) Élaboration à dire d'experts de systèmes de culture innovants, in: Reau R., Doré T. (Eds.), Systèmes de Culture Innovants et Durables: Quelles méthodes pour les mettre au point et les évaluer ? Educagri Editions, Dijon, pp. 71-89.

Loyce Ch., Rellier J.P., Meynard J.M. (2002) Management planning for winter wheat with multiple objectives (1): the BETHA system, Agr. Syst. 72, 9-31.

Ma L. (2006) Knowledge Representation Under Inherent Uncertainty in a Multi-Agent System for Land Use Planning, Ph.D. Thesis, Eindhoven University of Technology, Eindhoven, The Netherlands, $164 \mathrm{p}$.

Matthies M., Giupponi C., Ostendorf B. (2007) Environmental decision support systems: current issues, methods and tools, Environ. Modell. Softw. 22, 123-127.

Maystre L.Y., Pictet J., Simos J. (1994) Méthodes multicritères ELECTRE, Presses Polytechniques et Universitaires Romandes, Lausanne.

Mazzetto F., Bonera R. (2003) MEACROS: a tool for multi-criteria evaluation of alternative cropping systems, Eur. J. Agron. 18, 379-387.

Meul M., Van Passel S., Nevens F., Dessein J., Rogge E., Mulier A., Van Hauwermeiren A. (2008) MOTIFS: a monitoring tool for integrated farm sustainability, Agron. Sustain. Dev. 28, 321-332. 
Meyer-Aurich A. (2005) Economic and environmental analysis of sustainable farming practices - a Bavarian case study, Agr. Syst. 86, 190-206.

Meynard J.M. (2008) Produire autrement : réinventer les systèmes de culture, in: Reau R., Doré T. (Eds.), Systèmes de Culture Innovants et Durables : Quelles méthodes pour les mettre au point et les évaluer ? Educagri Editions, Dijon, pp. 11-27.

MSA (Mutualité Sociale Agricole, 2006) Approche statistique des risques professionnels des non salariés agricoles : Synthèse nationale, Caisse Centrale de la MSA - Santé-Sécurité au Travail, 6 p. http:// www.msa.fr/files/msafr/msafr_1166005823772_APPROCHE_ DES_RISQUES_PROFESSIONNELS_DES_NON_SALARI_S_ AGRICOLES_2006.pdf.

Munda G. (2005) Multiple criteria decision analysis and sustainable development, in: Figueira J., Greco S., Ehrgott M. (Eds.), Multiple Criteria Decision Analysis: State of the Art Surveys, SpringerVerlag, New York.

Munda G., Nijkamp P., Rietveld P. (1994) Qualitative multicriteria evaluation for environmental management, Ecol. Econ. 10, 97-112.

Neher D. (1992) Ecological sustainability in agricultural systems. Definition and measurement, J. Sustain. Agr. 2, 51-61.

Osinski E., Meier U., Büchs W., Weickel J., Matzdorf B. (2003) Application of biotic indicators for evaluation of sustainable land use-current procedures and future developments, Agr. Ecosyst. Environ. 98, 407-421.

Pacini C., Wossink A., Giesen G., Vazzana C., Huirne R. (2003) Evaluation of sustainability of organic, integrated and conventional farming systems: a farm and field-scale analysis, Agr. Ecosyst. Environ. 95, 273-288.

Paoletti M.G. (1999) The role of earthworms for assessment of sustainability and as bioindicators, Agr. Ecosyst. Environ. 74, 137-155.

Parisi V., Menta C., Gardi C., Jacomini C., Mozzanica E. (2005) Microarthropod communities as a tool to assess soil quality and biodiversity: a new approach in Italy, Agr. Ecosyst. Environ. 105, 323-333.

Phillis Y.A., Andriantiatsaholiniainan L.A. (2001) Sustainability: an illdefined concept and its assessment using fuzzy logic, Ecol. Econ. $37,435-456$.

Reau R., Landé N. (2006) Evaluation a priori de systèmes de culture innovants conçus par des experts et adaptés a des contextes régionaux, Final Report on Work Package\#1, ADAR project "Systèmes de cultures innovants", $27 \mathrm{p}$.

Reau R. et al. (2006) Actes du Séminaire "Systèmes de culture innovants" - Projet ADAR Systèmes de culture innovants piloté par le CETIOM, Versailles, 27 juin 2006.

Rosnoblet J., Girardin P., Weinzaepflen E., Bockstaller C. (2006) Analysis of 15 years of agriculture sustainability evaluation methods, in: Fotyma M., Kaminska B. (Eds.), Proceedings of the 9th ESA Congress. Warsaw, Poland, September 4-6, 2006, pp. 707708 .

Rossing W.A.H., Meynard J.M., Van Ittersum M.K. (1997) Model-based explorations to support development of sustainable farming systems: case studies from France and the Netherlands, Eur. J. Agron. 7, 271-283.
Saaty T.L. (1980) The Analytic Hierarchy Process, McGraw-Hill, New York.

Sadok W., Angevin F., Bergez J.-E., Bockstaller C., Colomb B., Guichard L., Reau R., Doré T. (2008) Ex ante assessment of the sustainability of alternative cropping systems: implications for using multicriteria decision aid methods. A review, Agron. Sustain. Dev. 28, $163-174$.

Sebillotte M. (1990) Système de culture, un concept opératoire pour les agronomes, in: Combe L., Picard D. (Eds.), Un point sur les systèmes de culture, INRA éditions, Paris, pp. 165-196.

Schaller N. (1993) The concept of agricultural sustainability, Agr. Ecosyst. Environ. 46, 89-97.

Shrestha R.K., Alavalapati J.R.R., Kalmbacher R.S. (2004) Exploring the potential for silvopasture adoption in South-central Florida: an application of SWOT-AHP method, Agr. Syst. 81, 185-199.

Spoor G., Tijink F.G.J., Weisskopf P. (2003) Subsoil compaction: Risk, avoidance, identification and alleviation, Soil Till. Res. 73, 175182.

Steen I. (1998) Phosphorus availability in the 21st Century: management of a non renewable resource, Phosphorus Potassium 217, 25-31.

Stewart W.M., Hammond L.L., Van Kauwenbergh S.J. (2005) Phosphorus as a Natural Resource, in: Sims J.T., Sharpley A.N. (Eds.), Agriculture and the Environment, Agronomy Monograph No. 46, ASA, CSSA, SSSA, Madison, Wisconsin 53711 USA, pp. 3-22.

Van Cauwenbergh N., Biala K., Bielders C., Brouckaert V., Franchois L., Garcia Cidad V., Hermy M., Mathijs E., Muys B., Reijnders J., Sauvenier X., Valckx J., Vanclooster M., Van der Veken B., Wauters E., Peeters A. (2007) SAFE - A hierarchical framework for assessing the sustainability of agricultural systems, Agr. Ecosyst. Environ. $120,229-242$

van de Zande J.C. (1991) Computed reconstruction of field traffic patterns, Soil Till. Res. 19, 1-15.

Van Ittersum M., Ewert F., Heckelei T., Wery J., Alkan Olsson J., Andersen E., Bezlepkina I., Brouwer F., Donatelli M., Flichman G., Olsson L., Rizzoli A., van der Wal T., Wien J.E., Wolf J. (2007) Integrated assessment of agricultural systems a component-based framework for the European Union (SEAMLESS), Agr. Syst. 96, $150-165$.

Vereijken P. (1997) A methodical way of prototyping integrated and ecological arable farming systems (I/EAFS) in interaction with pilot farms, Eur. J. Agron. 7, 235-250.

Vilain L., Boisset K., Girardin P., Guillaumin A., Mouchet C., Viaux P., Zahm F. (2008) La méthode IDEA indicateur de durabilité des exploitations agricoles - guide d'utilisation (ed collectif O.), Educagri éditions, Dijon, 184 p.

Walter C. (2006) Sustainability assessment of land use systems, Ph.D. Thesis, University of Hannover, Hannover, Germany, $180 \mathrm{p}$.

Zander P., Kächele H. (1999) Modelling multiple objectives of land use for sustainable development, Agr. Syst. 59, 311-325. 